\title{
SOME OBSERVATIONS ON THE DOWNY MILDEW DISEASE OF GRAPE VINE CAUSED BY PLASMOPARA VITICOLA IN JAFFNA
}

\author{
NIRANJANI RAMANATHAN AND A. SIVAPALAN \\ Department of Botany, University of Jaffna, Jaffna, Sii Lanka.
}

(Date of receipt : 29 January 1987)

(Date of acceptance: 15 September 1987)

\begin{abstract}
Frequent field observations made in the vineyards of Jaffna showed that the disease is confined to the rainy: season of the year. The development of symptoms on various parts of grape vine has been observed. Invasion of the host tissue was accompanied by changes in colour and appearance of the affected portion. Sporangia of Plasmopara viticola germinated after $18 \mathrm{~h}$ of incubation at $25^{\circ} \pm 1^{\circ} \mathrm{C}$ and $100 \% \mathrm{r}$ and their single thick germ tubes penetrated the stomata by about $48 \mathrm{~h}$. Penetration strictly occurred through stomata. Following penetration the fungus formed intercellular hyphae and colonised the spongy and pallisade parenchyma cells of the host. The external appearance of sporulating structures took about five days and this occurred strictly through the stomata. The lesions remained productive upto the ninth day. during incubation.
\end{abstract}

\section{Introduction}

Grape vine (Vitis vinifera) cultivation in Sri Lanka has been a success and the grapes produced in the vineyards of Jaffna and the eastern regions are sufficient to meet the needs of the whole country. In tropical climates the grape vine is evergreen and it has been found in the Jaffna region that by forcing the vine into two growth cycles, one in the wet season and the other in the dry season, it produces profitably.

The most destructive fungal disease of grape vine is the downy mildew caused by Plasmopara viticola (Berk. \& Curt.) Berl. \& de Toni. This disease has been observed in almost all the vineyards in the Jaffna region during the rainy season and periods of dew from October to March. The development of the fungus was favoured by the high humidity and low temperature of rainy weather and the presence of dew. There was a gradual weakening of the plants due to infection and the yield was reduced because of the severe yearly attacks by the fungus. There have been instances where grape cultivation was completely abandoned as a result.

The present investigation was made in order to obtain basic information with regard to the occurrence and biology of the fungus in the vineyards in the Jaffna region. This is indeed the first report of such a study in Sri Lanka on the downy mildew disease of grape vine. 


\section{Experimental}

Frequent field observations were made in the vineyards of Jaffna and information regarding the occurrence of the disease and the development of symptoms was recorded.

Following the observations on the development of the symptoms on various parts of the grape vine, the different developmental stages of the fungus, namely the germination of sporangia, internal colonization and sporulation, were examined in detail under laboratory conditions.

For the laboratory experiments healthy mature leaves were collected from the field, brought to the laboratory and maintained at a temperature of $25^{\circ} \mathrm{C} \pm 1$ in an illuminated incubator (Gallenkamp Cooled Incubator . . . . .). These materials were used as the source of host tissue throughout the experiment. All observations were made on the grape vine variety Israel blue which is the commonly cultivated variety in Sri Lanka.

Inoculum was obtained from mature vine leaves infected with Plasmopara viticola. These affected leaves collected from the field were placed in pairs, under surface to under surface, in plastic boxes and kept in refrigerators at $4^{\circ} \mathrm{C}$. When required these leaves were taken out and shaken in a petri dish of sterile distilled water (SDW).The sporangial suspension thus prepared was used to inoculate fresh sets of leaves or leaf discs of $2 \mathrm{~cm}$ diameter. The concentration of the sporangial suspension was adjusted to $2.4 \times 10^{7}$ sporangia $\mathrm{ml}^{-1}$ with SDW.

Inoculation was done by spraying the sporangial suspension with a hand sprayer. Leaf discs of $2 \mathrm{~cm}$ diameter or entire leaves were inoculated on the lower surface and kept on moist filter paper discs in Petri dishes. The Petri dishes were incubated at $25^{\circ} \pm 1{ }^{\circ} \mathrm{C}$ and at $100 \% \mathrm{rh}$ in an illuminated incubator.

Assessment of the development of the fungus was one as follows:-

\subsection{Germination of sporangium}

Five inoculated leaf discs were removed from the illuminated incubator at two-hour intervals during incubation and sellotape impressions of the inoculated surface were prepared. The preparations were stained with cotton blue in lactophenol and mounted in $50 \%$ glycerine on a clean glass slide. The impressions were observed under a light microscope ( $x$ 400) for germination of sporangia. The numbers of germinated and ungerminated sporangia were determined from counts of 200-300 sporangia in five microscopic fields, randomly selected from each of the five leaf discs. A sporangium was 
considered to have germinated when the germ tube length exceed its breadth. ${ }^{4}$ From the above data the mean percentage germination of sporangia was determined. The length of germ tube of about fifty germinated sporangia was measured after 24 hours of incubation, under the microscope $(x 400)$ with the use of a calibrated eye-piece graticule.

\subsection{Infection}

Observations were made on hand sections and scrapings of the host leaf, taken at six-hour intervals after incubation. The time of appearance of initial symptoms and formation of visible lesions were noted.

The amount of infection was determined at 24-hour intervals after inoculation by measuring the diameter of visible lesions. The lesions were assumed to be circular and the diameter of each lesion was measured thrice at right angles to each other, under the microscope (x 40). The amount of infection was expressed as mean percentage area of infection taken from sets of five leaves.

\subsection{Sporulation}

The inoculated leaf discs were incubated at $25^{\circ} \pm 1^{\circ} \mathrm{C}$ and $100 \% \mathrm{r} \mathrm{h}$ sets of five leaf discs were removed from the illuminated incubator at six-hour intervals commencing 48 hours after inoculation and assessed for sporulation, by the following two methods:

\subsubsection{Sporangiophore production}

The incubated leaf discs were boiled in 1:1 acetic acid-acetone mixture in a water bath for 15 minutes to decolourise the host tissue. After decolourisation the host material was placed on a glass slide, stained with cotton blue in lactophenol, mounted in glycerine and covered with a clean cover slip. These preparations were observed under the microscope and the number of sporangiophores present per microscopic field (x 40) was determined. These values were then converted to number of sporangiophores produced per $\mathrm{mm}^{2}$ area of the host tissue.

\subsubsection{Sporangia production}

The incubated leaf discs were shaken with one $\mathrm{ml}$ of SDW in Mc Carty bottles for one minute. The number of sporangia present in the sporangial suspension was determined by using a haemocytometer. These values were then converted to number of sporangia produced per $\mathrm{cm}^{2}$ area of the leaf surface. 


\subsection{Perennation of the fungus}

The perennation of the fungus during unfavourable seasons has in most cases been ascribed to the production of oospores as reported by Lafon \& Built. ${ }^{3}$ Attempts were made to look for these by periodical sectioning of infected leaves fallen on the ground and leaf debris during the disappearance of the fungus.

\section{Results}

\subsection{Development of symptoms on grape vine}

All green parts of the grape vine, namely the leaves, tendrils, stems, inflorescences and berries were found to be affected by the fungus. Invasion of the host tissue was accompanied by changes in colour and appearance of the affected portion. The colour changes and symptoms produced on various parts of grape vine are given below:

\subsubsection{Leaves}

The leaf was found to be the most susceptible tissue to fungal attack. The first evidence of infection was the appearance of light yellow translucent spots or 'oil spots' 'on the upper leaf surface resulting from the internal colonization by the fungus within the host tissue. The leaves later became mottled and soon white patches of downy growth of the sporulating structures were formed on the lower surface of the leaves. These were due to the sporangiophores and sporangia of the fungus. The sporangiophores were branched and were of determinate growth. These were found to arise singly or in tufts from the epidermis strictly through the stomata. The branches of sporangiophores were found to arise perpendicularly from the main.axis; the branchlets produced single elliptical sporangia at their terminal ends, on sterigmata. The mature sporangiophores were hyaline and did not take up the stain cotton blue in lactophenol.

When the disease became severe in a vineyard, the lower surface of the leaves was fully covered with the fungus. The lesions covered with the sporulating structures turned brown and finally became necrotic. Badly infected leaves became $d r y$ and crumpled and finally dropped from the plant. Vine plants that had been poorly cared for were completely defoliated due to the infection.

\subsubsection{Stems}

Stems were found to be affected only during growth up to a distance of about $80-100 \mathrm{~mm}$ from the apex. The infected portions of the stems deve- 
loped brown streaks and at later stages of infection they became hooked at the tips. The nodes were found to be more susceptible than the internodes. No sporangiophore production was observed on the surface of the stems.

\subsubsection{Tendrils}

Young tendrils were infected by the fungus and showed symptoms of infection as brown streaks. The symptoms first appeared at the tips and then gradually spread to other portions of tendrils. Here too the tendrils became hooked at the tips at later stages of infection. No external production of sporangia was observed.

\subsubsection{Inflorescence}

Brown irregular patches or longitudinal streaks appeared on the inflorescence axes due to fungal attack; very often the infected inflorescence curled up, became dry and failed to develop fruits. On the inflorescence axis no external production of sporangia was observed. The affected inflorescences were often shed from the plant.

\subsubsection{Berries}

Downy mildew attack on the berries was apparent from the initial formation until ripening. After flowering, the developing bunches which were subjected to fungal attack showed yellowish brown patches of infection due to the penetration of the fungus through stomata of the stalks and the fruits. As the berries matured, the diseased parts became brown but at no stage was external production of sporangia observed. However, white masses of sporulating structures were produced on the stalks of the berries where the stomata present were still functioning. Berries severely affected at an early stage failed to develop further, but when affected at a later stage of development became shrivelled and were found to be shed easily from the plants. During the period of investigation it was not possible to observe the white cottony growth of the mildew on parts other than leaves in the fields.

\subsection{Germination of Sporangium}

Sporangial suspensions when examined under the microscope showed presence of three stages of sporangia depending on the maturity. Sporangia of the first category were immature, small $(20-26 \mu \mathrm{m}$ in length and $12-16 \mu \mathrm{m}$ in breadth), finely granular and were filled with inclusions. These sporangia readily took up the stain - cotton blue in lactophenol. Their hyaline wall was thin and uniform in thickness. Papillae were not distinct in these sporangia. These sporangia were capable of germinating after about 48 hours of incubation. Sporangia of the second category were fairly 
mature $(24-32 \mu \mathrm{m}$ in length and $15-18 \mu \mathrm{m}$ in breadth), slightly brownish with dense inclusions and oil globules and were found to germinate directly within 24 hours forming single thick germ tubes. Sporangia of this type and their germ tubes readily took up the stain. The germ tubes were found to arise from the papillary ends. Sporangia of the third category were large $(30-37 \mu \mathrm{m}$ in length and $15-18 \mu \mathrm{m}$ in breadth) brownish and coarsely granular. These did not germinate directly by producing single germ tubes; instead, they germinated by producing zoospores. Presence of zoospores was only observed in the sporangia of this category. Counts on the number of zoospores present in these sporangia indicated that about $4-16$ zoospores were usually produced from a single sporangium, irrespective of the conditions in which these sporangia were formed. The zoospores were about $2 \mu \mathrm{m}$ in diameter on an average. The sporangia have been observed to burst open at the papillary end and the zoospores were found to escape through this opening. The liberated zoospores have been observed to reach and germinate on the lower leaf surface of vine leaves. Germination by zoospore formation has been found to be less frequent than direct germination of sporangia. In all experiments on germination, the germination of only the second category of sporangia was assessed.

In the study of germination of sporangia, inoculated leaf discs incubated at $25^{\circ} \pm 1^{\circ} \mathrm{C}$ and at $100 \% \mathrm{rh}$ in an illuminated incubator were assessed on the germination after short periods Sporangia started to germinate after about 16 hours producing thick, single germ tubes. However, a considerable number of sporangia was found to have germinated 18 hours after incubation. The germination values increased significantly up to 48 hours (Table 1).

The length of germ tube of germinated sporangia increased with increase in period of incubation (Table 1) but since the germinated sporangia were found to reach and penetrate through the stomata or perish after 48 hours, it was difficult to make further measurement on the germ tube length after 48 hours of incubation.

\subsection{Internal colonization}

The germ tubes that penetrated the stomata were found to reach the substomatal cavity on the lower surface of the host leaf. Observations showed that on the lower leaf surface, one stoma was penetrated by about three germ tubes on an average but the number varied from 1 to 5 . The average number of stomata per microscopic field $(x 400)$ on the lower surface of the host was found to be 6 and about $50 \%$ of the stoma were penetrated. It was also observed that the penetration of the host occurs strictly through stomata. Direct penetration through the epidermis or by other means has not been observed. 
Table 1. The germination of sporangia and growth of germ tube of Plasmopara viticola on detached leaves of grape vine at $25^{\circ} \mathrm{C}$ and $100 \%$ relative humidity.

\begin{tabular}{ccc}
\hline $\begin{array}{c}\text { Period of incubation } \\
\text { (hours) }\end{array}$ & $\begin{array}{c}\text { Mean \% germination } \\
\text { gean tength of }\end{array}$ \\
\hline 10 & 0 & 0 \\
12 & 0 & 0 \\
14 & 0 & 0 \\
16 & $3.3 \mathrm{a}$ & 25 \\
28 & $39.5 \mathrm{~b}$ & 42 \\
20 & $42.2 \mathrm{c}$ & 83 \\
22 & $44.6 \mathrm{~d}$ & 91 \\
24 & $45.8 \mathrm{e}$ & 103 \\
48 & $51.6 \mathrm{f}$ & 164 \\
72 & $51.4 \mathrm{f}$ & 166 \\
\hline
\end{tabular}

Note :- Values denoted by different letters are statistically different.

The germinated sporangia which entered the host tissue formed intercellular hyphae and colonised the spongy and the palisade parenchyma cells of the host. Globular haustoria with short necks were observed inside these host cells.

Following the internal colonization, the host tissue changed in colour from green to pale yellow depending on the severity of infection. This discolouration or the appearance of oil spots of infections on the upper leaf surface was observed 60 hours after incubation and was the first visible symptom of infection.

The mean percentage area of infection increased with increase in period of incubation and reached $100 \%$ by the twelfth day after incubation (Table 2).

\subsection{Sporulation}

Following internal colonization, the emergence of sporangiophores took place through the stomata on the lower leaf surface. The first emergence of sporangiophore initials was observed around 65 hours after incubation, and clusters of sporangiophores continued to emerge out of the stomata after $\mathbf{7 2}$ hours of incubation. About $25 \%$ of the total stomata present in a micros- 
Table 2. Development of infection by Plasmopara viticola on detached leaves of grape vine at $25^{\circ} \mathrm{C}$ and $100 \%$ relative humidity.

\begin{tabular}{cc} 
Period of incubation (days) & Mean \% area of \\
\hline 0 & 0 \\
1 & 0 \\
2 & 0 \\
3 & 0 \\
4 & 2.1 \\
5 & 28.6 \\
6 & 52.0 \\
7 & 86.4 \\
8 & 98.1 \\
9 & 100.0 \\
10 & 100.0
\end{tabular}

copic field (x 400) showed emergence of sporangiophore initials. Mature sporangiophores were present only on the fifth day after incubation. The mature sporangiophores were branched or unbranched and varied in axial length from $116 \mu \mathrm{m}-286 \mu \mathrm{m}$ and in breadth from $16-26 \mu \mathrm{m}$. They produced $3-7$ branches and $3-7$ branchlets on each branch. The mature sporangiophores emerged out of the stomata at the rate of about 4 per stoma on an average but the number varied from $1-12$ per stoma, on a lesion that was five days old.

In such a lesion, about $90 \%$ of the total stomata in a microscope field ( $x$ 400) showed presence of sporangiophores. The number of immature sporangiophores increased up to the sixth day after incubation and gradually decreased thereafter. At the same time the number of mature sporangiophores increased up to the eighth day and then became static (Table 3). By this time the lesion had attained its full growth.

The length measurements of sporangiophores showed that the sporangiophores increased in length with time from the third day after incubation. The increase was rapid up to the eighth day and thereafter the length of the sporangiophore remained more or less constant (Table 4).

Sporulation or sporangia production was measured by determining the amount of sporangia of the three categories produced per sq. $\mathrm{mm}$ area of the lesion (Table 5). The amount of immature sporangia produced was high on the fifth day after incubation and thereafter it started decreasing. From the 
Table 3. The production of sporangiophores of Plasmopara viticola on detached leaves of grape vine at $25^{\circ} \mathrm{C}$ and $100 \%$ relative humidity.

\begin{tabular}{crrr}
\hline Period of incubation & \multicolumn{3}{c}{$\begin{array}{c}\text { Mean number of sporangiophores/ } \\
\mathrm{mm}^{2} \text { area of host leaf }\end{array}$} \\
& i.s. & m.s. & Total \\
\hline 3 & 53 & 0 & 53 \\
4 & 107 & 10 & 117 \\
5 & 140 & 80 & 220 \\
6 & 180 & 210 & 390 \\
7 & 145 & 364 & 514 \\
8 & 10 & 570 & 580 \\
9 & 0 & 570 & 570 \\
\hline
\end{tabular}

i.s. = Immature sporangiophores.

m.s. = Mature sporangiophores.

Table 4. Growth of sporangiophore of Plasmopara viticola on detached leaves of grape vine at $25^{\circ} \mathrm{C}$ and $100 \%$ relative humidity.

\begin{tabular}{cccc}
\hline Period of incubation (days) & \multicolumn{2}{c}{$\begin{array}{c}\text { Length of sporangiophores } \\
\text { i.s. } \mathrm{m})\end{array}$} \\
& & & Mean \\
\hline 3 & 56 & 0 & 56 \\
4 & 122 & 147 & 124 \\
5 & 123 & 270 & 176 \\
6 & 122 & 277 & 205 \\
7 & 138 & 282 & 260 \\
8 & 0 & 286 & 286 \\
9 & 0 & 285 & 285 \\
10 & 0 & 283 & 283 \\
11 & 0 & 285 & 285 \\
& & & \\
\hline
\end{tabular}

i.s. = Immature sporangiophores.

m.s. = Mature sporangiophores. 
Table 5: Production of sporangia of Plasmopara viticola on detached leaves of grape vine at $25^{\circ} \mathrm{C}$ and $100 \%$ of relative humidity.

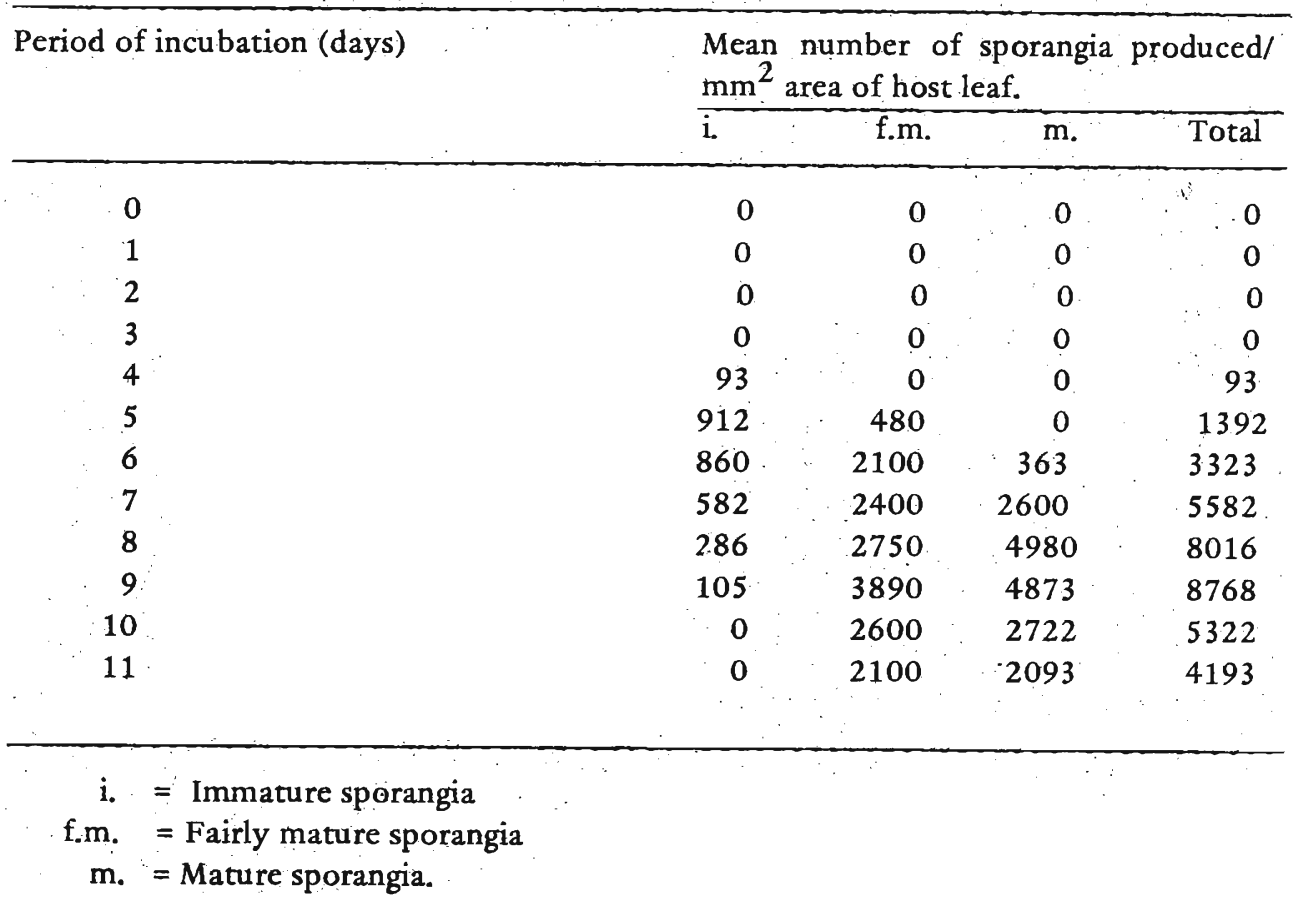

fourth day onwards the number of fairly mature sporangia increased in number and reached a maximum value after nine days The amount of fairly mature sporangia then decreased slowly and became static on the eleventh day. Similarly the amount of mature sporangia present increased from the fifth day and reached its maximum value between the eighth and the ninth days. The value became static on the eleventh day after decreasing slowly.

During these investigations oospores have never been observed though attempts were made to look for them.

\section{Discussion}

It has been observed for several years that the downy mildew disease of grape vine is a destructive fungal disease. This is usually severe during periods of high humidity and low temperature or rainy weather conditions.

The fungus responsible for grape vine downy mildew Plasmopara viticola (Berk. \& Curt.) Berl. \& de Toni. is an obligate parasite which cannot 
therefore be easily cultivated in vitro or on inert nutritive media.

Observations on the occurrence of downy mildew in the vineyards showed that infections begin in September or October when the rainy season starts and last till April with the greatest severity of the disease observed in late February or March.

Almost all green parts of the vine were affected by this fungus as already observed by Ramanathan and Sivapalan, ${ }^{6}$ but the most prominent symptoms were on leaves. It was suggested by Rives and Lafon ${ }^{8}$ that only the young actively growing organs are susceptible to infection. The infections occurred on the lower leaf surface and undoubtedly through the stomata, as already confirmed by Ravaz and Verge. ${ }^{7}$

The first symptom of infection was the formation of translucent yellow 'oil spots' on the upper surface which is followed by appearance of a white downy growth of sporulating structures on the under leaf surface corresponding to the oil spots. Apart from leaves, the berries, tendrils, inflorescences and stems too developed infections 5 but at no stage was external production of sporangiophores observed on parts other than leaves during this study. Infection on these parts appeared as only brown, irregular or linear patches or streaks as a result of internal colonization. However there are reports by several authors on the formation of sporangiophores and sporangia on the surface of berries and inflorescences. 3 . But these workers claim that these organs are susceptible as long as the stomata on them remain functioning for the reason that penetration of host and emergence of sporangiophores occur strictly through stomata.

Weakening of leaves due to infection led to their premature senescence. The yield and life span of the grape vine was highly reduced by the downy mildew attacks.

The infection process of the fungus was initiated by germination of sporangia during favourable conditions. Sporangia directly germinated by emitting the entire contents and forming thick germ tubes which penetrated stomata on the host leaf and colonised the inner tissues. The external appearance of sporulating structures through stomata of the lower leaf surface took about five days and lesions remained productive up to the ninth day.

The perennation of the fungus during unfavourable seasons has been attributed by several workers 3 to the sexual reproductive structures known as the oospores. Observations towards the end of the season failed to reveal the presence of oospores or the mode of perennation of the fungus. The disease is completely absent during the season from May to September. In these circumstances the mode of overwintering may be by preservation of mycelia which remain between the bud scales in diseased plants until budburst as suggested by Galet ${ }^{2}$ and Boubals. ${ }^{1}$ 


\section{Acknowledgements}

We wish to express our sincere thanks to the Natural Resources, Energy and Science Authority of Sri Lanka for funding this project.

\section{References}

1. BOVBALS, , D. (1977) "Early spring and grape vine downy mildew", Printems precou et mildiou de la vigne. Progress Agricola et viticola 94 (6):185.

2. GALET, P. (19.77) "Les Maladies et les parasites de la vigne" Tome 1, Montpellier. Imprimerie du Paysan du Midi.

3. LAFON, R. \& BULIT, J.C. (1981) "Downy mildew of the vine". The Downy Mildews Ed. D.M. Spencer 28: $601-603$.

4. MANNERS, J.G. \& HOSSAIN, S.M.M. (1963) "Effect of Temperature and humidity on conidial germination in Erysiphe graminis". Trans. Britisb Mycological Society, 46: $225-234$.

5. RAMANATHAN, N. (1985) "Studies on the downy mildew disease of grape vine caused by Plasmopara viticola (Berk. \& Curt.) Berl. \& de Toni". M. Phil Thesis, University of Jaffna, Sri Lanka.

6. RAMANATHAN, N. \& SIVAPALAN, A. (1982). "The development of downy mildew disease on grape vine". Proc. Sri Lanka Assoc. Advmt. Sci, 38.

7. RAVAz, L. \&.VERGE, G. (1914). Ann. Ec. Nation. Sup. Agron. Montpellier Ns, XIV, $169-199$.

8. RIV́ES, M. \& LAFON, R. (1972). Vitis. Bd. 11: 34-52. 